\title{
ONTOLOGICAL ANALYSIS OF INTEGRATED PROCESS MODELS: TESTING HYPOTHESES
}

\author{
Peter Green, Michael Rosemann \\ Dr Peter Green \\ Department of Commerce \\ University of Queensland \\ Ipswich, Australia \\ p.green@mailbox.uq.edu.au \\ +61 (0)73381 1121 \\ $+61(0) 733811029$
}

\begin{abstract}
Integrated process modeling is achieving prominence in helping to document and manage business administration and IT processes in organizations. The ARIS framework is a popular example for a framework of integrated process modeling not least because it underlies the 800 or more reference models embedded in the world's most popular ERP package, SAP R/3. This paper demonstrates the usefulness of the Bunge-Wand-Weber (BWW) representation model for evaluating modeling grammars such as those constituting ARIS. It reports some initial insights gained from pilot testing Green and Rosemann's (2000) evaluative propositions. Even when considering all five views of ARIS, modelers have problems representing business rules, the scope and boundary of systems, and decomposing models. However, even though it is completely ontologically redundant, users still find the function view useful in modeling.
\end{abstract}

\section{INTRODUCTION}

The aim of this paper is to report the results of some initial data gathering and testing of propositions that derived from an ontological evaluation of integrated process modeling (Green \& Rosemann 2000). This evaluation used the ARIS framework popularized by Scheer (1999) for integrated process modeling. Over the last ten years, process management has received increased attention within the business administration and information systems communities. This increased attention derives from the fact that understanding and managing processes are tasks critical to achieving benefits from such new management philosophies as Total Quality Management, Activity-based Costing, and Business Process Re-engineering (Hammer 1990; Davenport 1993). Accordingly, integrated process modeling as a means of documenting, analyzing, and evaluating processes has also risen to prominence in organizations over the last decade.

Scheer's ARIS framework was selected as the example of integrated process modeling for the ontological evaluation for a number of reasons. First, it integrates five views of the process (data, function, organization, output, and process) to provide the user with a comprehensive modeling framework that can be used to generate relatively easy-to-understand process models. Second, its implementation through ARIS Toolset claims in excess of 20,000 licenses worldwide. Accordingly, there appears to be a large, mature user base against which analytical propositions can be tested. Finally, ARIS underlies the reference models provided in one of the world's most popular Enterprise Resource Planning (ERP) packages worldwide at the present time, SAP R/3.

This work is motivated by the desire to develop and begin testing the propositions generated by Green and Rosemann's (2000) ontological evaluation of Scheer's ARIS integrated process modeling framework. In doing so, we can develop and initially test a data-gathering instrument. We can use the instrument to collect some preliminary data on the propositions. From the results, we can refine the data-gathering instrument but, more importantly, we can begin providing some insights into the usefulness of the ontological evaluation for process modelers using ARIS. Accordingly, this paper reports the formulation of a testing instrument and essentially its initial pilot testing with a cohort of post-graduate information systems students studying process modeling.

The paper unfolds in the following manner. First, some further background is provided on what is ontology and how the ontological evaluation was performed. Next, Green and Rosemann's (2000) analytical results are summarized. Then, the research methodology used in this work is explained. Following that explanation, the results of this initial work are presented and discussed. Finally, we explain briefly how this work will be progressed.

\section{BACKGROUND}

As grammars for information systems analysis and design have proliferated over the years, researchers and practitioners alike have attempted to determine objective bases on which to compare, evaluate, and determine when to use these grammars (e.g., Batra, Hoffer, \& Bostrom 1990; Karam \& Casselman 1993). Throughout the 80 's and 90 's, and now into the new millennium however, it has become increasingly apparent to many researchers that without a theoretical foundation on which to base information systems analysis and design (ISAD) grammar specification, incomplete evaluative frameworks of factors, features, and facets would continue 
to proliferate. Furthermore, without a theoretical foundation, one framework of factors, features, or facets is as justifiable as another for use (Floyd 1986; Bansler \& Bodker 1993).

Wand and Weber (1989a, 1989b, 1990a, 1990b, 1991, 1993, 1995) have investigated the branch of philosophy known as ontology (or meta-physics) as a foundation for understanding the process in developing an information system. Ontology is a well-established theoretical domain within philosophy dealing with models of reality. Wand and Weber (1989b, 1990a, 1990b, 1993, 1995) and Weber (1997) have taken, and extended, an ontology presented by Bunge (1977) and applied it to the modeling of information systems. Their fundamental premise is that any ISAD modeling grammar must be able to represent all things in the real world that might be of interest to users of information systems; otherwise, the resultant model is incomplete. If the model is incomplete, the analyst/designer will somehow have to augment the model(s) to ensure that the final computerized information system adequately reflects that portion of the real world it is intended to simulate. The Bunge-Wand-Weber (BWW) (1989b, 1990a, 1990b, 1993, 1995) models consist of the representation model, the state-tracking model, and the good decomposition model. This work focuses on the representation model. The representation model defines a set of constructs that, at this time, are thought by the Wand and Weber to be necessary and sufficient to describe the structure and behavior of the real world.'

Weber (1997) clarifies two major situations that may occur when an ISAD grammar is analyzed according to the representation model. After a particular ISAD grammar has been analyzed, predictions on the modeling strengths and weaknesses of the grammar can be made according to whether some or any of these situations arise out of the analysis.

1. Ontological Incompleteness (or Construct Deficit) exists unless there is at least one ISAD grammatical construct for each ontological construct.

2. Ontological Clarity is determined by the extent to which the grammar does not exhibit one or more of the following deficiencies:

Construct Overload exists in an ISAD grammar if one ISAD grammatical construct represents more than one ontological construct.

Construct Redundancy exists if more than one ISAD grammatical construct represents the same ontological construct.

Construct Excess exists in an ISAD grammar when an ISAD grammatical construct is present that does not map into any ontological construct.

Accordingly, the representation model in particular provides a theoretical foundation on which ISAD grammars including those used in integrated process modeling frameworks like ARIS can be evaluated and developed.

\section{ONTOLOGICAL ANALYSIS OF ARIS AND DERIVED PROPOSITIONS}

Table 1 shows the detailed results of the Green and Rosemann (2000) evaluation of ARIS. Each of the five views of ARIS was analyzed using the ontological constructs of the BWW representation model.

Green and Rosemann (2000) explain that, examining only the process view, instances of ontological incompleteness lead to the following propositions:

1. Because there are no direct representations for thing, class, and/or kind, users will lack conceptual clarity regarding the object(s) in the real world to which the EPC relates. The EPC can represent indirectly attributes of the thing (business object) as attributes of the function type but not the thing itself. As Weber (1997) explains, the world is made up of things. Things in the world are identified via their properties; not the other way round. Accordingly, some other symbol/grammar/view will be needed in conjunction with the process view to overcome this ontological deficiency. Modelers may well find the existence of the organizational and output views useful to overcome this deficiency because they provide symbols that give representation to individual things (instances) in the real world.

1 For a detailed description of the all the constructs in the representation model, see Green and Rosemann (2000) or Weber (1997). 


\begin{tabular}{|c|c|c|c|c|c|}
\hline Ontalogical Construet & Process View y & Data Vlew & Function Vlew 3,4 & Organizational Vhew & Coutpat Vew \\
\hline THING & & & & $\begin{array}{l}\text { Organizational unit, } \\
\text { position, user (instances) }\end{array}$ & $\begin{array}{l}\text { Product catalogue, } \\
\text { product model, bill of } \\
\text { materials (instances) }\end{array}$ \\
\hline $\begin{array}{l}\text { PROPERTY: } \\
\text { IN PARTICULAR } \\
\text { IN GENERAL } \\
\text { INTRINSIC } \\
\text { MUTUAL } \\
\text { EMERGENT } \\
\text { HEREDITARY } \\
\text { ATTRIBUTES }\end{array}$ & Function Type & $\begin{array}{l}\text { Attribute type, attribute } \\
\text { group }\end{array}$ & $\begin{array}{l}\text { Function Type } \\
\text { Attribute type, goal, goal } \\
\text { structure }\end{array}$ & $\begin{array}{l}\text { Location, qualification, } \\
\text { requirements, profile } \\
\text { Location, qualification, } \\
\text { requirements, profile } \\
\\
\text { Attribute type }\end{array}$ & Cost type, cost rate \\
\hline CLASS & & Entity type & & $\begin{array}{l}\text { Organizational type, } \\
\text { position, user (class) }\end{array}$ & $\begin{array}{|ll|}\text { Material } & \text { Output/Input, } \\
\text { Services }\end{array}$ \\
\hline KIND & & $\begin{array}{l}\text { Specialization } \\
\text { /generalization (IS-A) }\end{array}$ & \begin{tabular}{|l|} 
Specialization \\
/generalization (IS-A)
\end{tabular} & \begin{tabular}{|l|}
$\begin{array}{l}\text { Specialization } \\
\text { /generalization (IS-A) }\end{array}$ \\
\end{tabular} & $\begin{array}{l}\text { Specialization } \\
\text { /generalization (IS-A) }\end{array}$ \\
\hline STATE & $\begin{array}{l}\text { Event type (only the state } \\
\text { variables that trigger the } \\
\text { function) }\end{array}$ & & & & \\
\hline \multicolumn{6}{|l|}{$\begin{array}{l}\text { CONCEIVABLE } \\
\text { STATE SPACE }\end{array}$} \\
\hline STATE LAW & $\begin{array}{l}\text { Function type } \rightarrow \\
\text { connector } \rightarrow \text { Event type }\end{array}$ & $\begin{array}{l}\text { Specialization/generaliza } \\
\text { tion descriptors; } \\
\text { [Min, max.] cardinalities }\end{array}$ & \begin{tabular}{l|} 
Specialization/generaliza \\
tion descriptors
\end{tabular} & & \\
\hline \multicolumn{6}{|l|}{\begin{tabular}{ll|} 
LAWFUL & STATE \\
SPACE
\end{tabular}} \\
\hline EVENT & $\begin{array}{l}\text { Event type } \rightarrow \text { Function } \\
\text { type } \rightarrow \text { Event type }\end{array}$ & & & & \\
\hline PROCESS & $\begin{array}{l}\text { Process model } \\
\text { Function type }\end{array}$ & & $\begin{array}{l}\text { Function type, business } \\
\text { process } \\
\text { Process oriented function } \\
\text { decomposition }\end{array}$ & & \\
\hline \multicolumn{6}{|l|}{$\begin{array}{l}\text { CONCEIVABLE } \\
\text { EVENT SPACE }\end{array}$} \\
\hline TRANSFORMATION & Function type & & Function type & & \\
\hline $\begin{array}{l}\text { LAWFUL } \\
\text { TRANSFORMATION }\end{array}$ & $\begin{array}{l}\text { Event type } \rightarrow \text { connector } \\
\rightarrow \text { Function type }\end{array}$ & & & & \\
\hline \multicolumn{6}{|l|}{$\begin{array}{l}\text { LAWFUL } \\
\text { SPACE }\end{array}$} \\
\hline \multirow{2}{*}{\multicolumn{6}{|c|}{$\begin{array}{l}\text { HISTORY } \\
\text { ACTS ON }\end{array}$}} \\
\hline \multicolumn{3}{|l|}{ ACTS ON } & & & \\
\hline $\begin{array}{l}\text { COUPLING: } \\
\text { BNDING MUTUAL } \\
\text { PROPERTY }\end{array}$ & & $\begin{array}{l}\text { Relationship type (no } \\
\text { symbol for relationship } \\
\text { in grammar) }\end{array}$ & & Role & \\
\hline \multicolumn{6}{|l|}{ SYSTEM } \\
\hline $\begin{array}{l}\text { SYSTEM } \\
\text { COMPOSITION }\end{array}$ & & Cluster & & Organizational hierarchy & Product model hierarchy \\
\hline \multicolumn{6}{|l|}{$\begin{array}{l}\text { SYSTEM } \\
\text { ENVIRONMENT }\end{array}$} \\
\hline \multicolumn{6}{|l|}{ SYSTEM STRUCTURE } \\
\hline SUBSYSTEM & & Cluster & & Organizational object & Product modeling object \\
\hline \multicolumn{6}{|l|}{$\begin{array}{l}\text { SYSTEM } \\
\text { DECOMPOSITION } \\
\end{array}$} \\
\hline LEVEL STRUCTURE & \begin{tabular}{|l|}
$\begin{array}{l}\text { Series of function type or } \\
\text { event } \\
\text { decomposition indicators }\end{array}$ \\
\end{tabular} & & \begin{tabular}{|l|} 
Series of function type \\
decompsition indicators
\end{tabular} & $\begin{array}{l}\text { Organizational modeling } \\
\text { levels }\end{array}$ & \begin{tabular}{|l|} 
Product modeling levels \\
\end{tabular} \\
\hline EXTERNAL EVENT & \begin{tabular}{|l|}
$\begin{array}{l}\text { Start event type (no } \\
\text { ingoing arrow) }\end{array}$ \\
\end{tabular} & & & & \\
\hline STABLE STATE & $\begin{array}{l}\begin{array}{l}\text { End event type (no } \\
\text { outgoing arrow) }\end{array} \\
\end{array}$ & & & & \\
\hline \multicolumn{6}{|l|}{ UNSTABLE STATE } \\
\hline INTERNAL EVENT & $\begin{array}{l}\text { Event type } \rightarrow \text { Function } \\
\text { type } \rightarrow \text { Event type }\end{array}$ & & & & \\
\hline $\begin{array}{l}\text { WELL-DEFINED } \\
\text { EVENT }\end{array}$ & $\begin{array}{l}\text { Event type } \rightarrow \text { Function } \\
\text { type } \rightarrow \text { Event type }\end{array}$ & & & & \\
\hline $\begin{array}{l}\text { POORLY-DEFINED } \\
\text { EVENT }\end{array}$ & & & & & \\
\hline
\end{tabular}

Table 1. BWW Representation Model Analysis of Integrated Process Modeling Views in ARIS.

2. Because the process view does not have representations for conceivable state space, lawful state space, conceivable event space, and lawful event space, a sufficient focus to identify all important state and transformation laws may not be present during modeling. These laws are the basis of what are known in systems analysis as business rules. Accordingly, problems may be encountered in capturing all the potentially important business rules of the situation. Moreover, the modeler may neglect to 
incorporate important process alternatives and the resultant model becomes less relevant or incomplete. Again, some other symbol/grammar may need to be employed in combination with the process view to overcome this deficiency.

3. Because the process view does not have representations for system, system composition, system environment, system structure, system decomposition, and coupling, the process view's usefulness for defining the scope and boundaries of the system being analyzed is undermined. Moreover, the usefulness of the process view for undertaking "good decompositions" (see, for example, Wand \& Weber 1995) during analysis is degraded. This issue is important because, in a comprehensive process modeling project, hundreds of individual process models could emerge. For the modeler using the process view, serious questions arise as to how to structure and factor the complexity of large projects into constituent models. Again, the use of some other symbol/grammar would appear necessary to overcome this deficiency.

When the analysis of the five views in combination in Table 1 is considered, some interesting propositions issue. 4. Even across the five views, no representations exist for conceivable state space, lawful state space, conceivable event space, or lawful event space. Again, a sufficient focus to identify all important state and transformation laws may not be present during modeling. Accordingiy, problems may be encountered in capturing all the potentially important business rules of the situation. For example, in ARIS, it is not clear how to specify which organizational units are responsible for a function under certain conditions without having to split the function type. Some other symbol/grammar may need to be employed to overcome this deficiency.

5. Across the five views, no representations exist for system, system environment, system structure, and system decomposition. Again, its usefulness for defining the scope and boundaries of the system being analyzed is undermined. Moreover, the usefulness of integrated process modeling for undertaking "good decompositions" during analysis would seem questionable. For example, there is no requirement in ARIS to perform corresponding decompositions between the interrelated process view and data view of a model. Indeed, because of this deficit situation, integrated process modeling would appear more useful in modeling existing situations to be modified (i.e., where a bottom-up approach is appropriate) as opposed to novel situations (i.e., where a top-down approach might be more appropriate).

A modeling grammar seems to be of high quality if it is ontologically complete and ontologically clear. In other words, every empty row in Table 1 indicates that even the entire ARIS approach incorporating the five views is ontologically incomplete. That is, certain ontological constructs do not appear, e.g., conceivable state space, conceivable event space, system, and system structure. These non-appearances form the bases of propositions 4 and 5. However, the converse argument could apply. The BWW representation model might be misspecified or wrong.

- Could the BWW representation model be over-engineered? Maybe it includes constructs that are not relevant. The ontological analyses of various modeling grammars to date (Wand \& Weber 1993, 1995; Weber \& Zhang 1996; Green 1997; Green \& Rosemann 2000) have consistently identified certain ontological constructs that do not have representations in the grammars examined, e.g., conceivable state space, conceivable event space, and lawful event space. The ontological analyses to date in themselves form an empirical study around this hypothesis of overengineering. One possible conclusion then could be the identification of the need for a reduction in the number of constructs thought to be sufficient and necessary in the $B W W$ representation model.

- Even if the BWW model is not over-engineered, most modeling grammars usually focus on modeling particular aspects of the real-world, e.g., statics, dynamics, processes, data, actors, actions, goals, and the like. Apparently, the objectives of the modeling grammar need to be taken into account during the ontological analysis. Such work identifies a need for individualization of the $B W W$ model by means of designing subsets and specializations of the BWW model.

- Finally, there may be a need for extending the $B W W$ model. Weber (1997) bas already extended the understanding of the ontological construct, property, by explaining the various types of property, e.g., property in general, property in particular. The growing importance of strategic enterprise modeling might lead to the explication of the BWW model to explicitly incorporate constructs to represent such abstract items as business objectives, strategies, goals, or knowledge.

Whether the situation exemplified in propositions 4 and 5 is indeed the case or the converse situation explained above holds is a question that can only be answered by evidence gained through a number of empirical investigations. The work reported in this paper contributes to the required body of evidence.

Green (1997) operationalized the Weber and Zhang (1996) concept of a minimal ontological overlapping (MOO) set of grammars. Effectively, grammars are combined to form a set that is as ontologically complete as possible. If the process view is selected as a starting point, the data view, and either the organizational or the output view 
would need to be employed to form the MOO set. The function view however appears to be ontologically redundant when compared to the MOO set of grammars. For example, construct redundancy and construct overload are displayed by the function type symbol in the function view. This situation suggested the following proposition:

6. Because the function view is completely ontologically redundant when compared to the combination of process view, data view, and either organizational view or output view, its use with the other views will undermine clarity and may cause confusion to users. For example, it is not clear whether function types should be entered in the function view or in the process view first. If a function type is split in the process view, this change is not necessarily reflected in the function view. This situation can lead to consistency problems, especially, if a modeling tool with an integrated repository is not available. Accordingly, limited usefulness and use of the function view is expected.

\section{RESEARCH METHODOLOGY}

We created a questionnaire to gather data on the propositions outlined above. We intended in the first instance to conduct a limited empirical study by administering this instrument to students from a postgraduate subject (Rein 1994). In this way, we might to achieve two goals. First, we could pilot test the raw instrument with a group of respondents. Second, we could gather some initial data on which we could gain some insight into our propositions. Based on the results of this initial testing, we could make a reasoned decision as to the usefulness of persisting with further, more comprehensive testing. In the longer term, we intended to administer our instrument to a sample of process modeling practitioners and academics both in Australia and internationally.

\section{Design of the Questionnaire}

The questionnaire consisted of 11 pages and was divided in three sections - A, B, and C. The purpose of section A was to collect information about the background of the respondents. This information included such items as years of general work experience, years of process modeling experience, years of experience with the ARISToolset, and the general purpose of the activities for which the integrated process modeling tool was used documentation of organizational or IT processes. Section B was constructed to gather data about the specific propositions. Moreover, it focused on how respondents working individually used process models in the ARISToolset. Section $\mathrm{C}$ by contrast asked for feedback regarding the use of integrated process modeling techniques when using ARIS-Toolset as a member in project teams.

Because there was no well-accepted, validated instrument known to the researchers for gathering data on such propositions, a new, raw instrument had to be created. Green (1996) developed and validated a similar instrument for gathering data on ontologically-based hypotheses involving the use of ISAD grammars in combination by analysts/designers when using structured upper CASE tools. This validated instrument was used as the initial basis for the formulation of the instrument for this study. ${ }^{2}$

\section{The Participants}

The participants of this pilot survey were identified because of their enrolment in an advanced post-graduate subject dealing with ARIS at an Australian university. Sixteen post-graduate students were identified in the subject called "Projects in Process Engineering". As a prerequisite for this subject, every participant had to been enrolled in the subject Process Engineering. In the Process Engineering subject, the students were taught the basics of Business Process Management. They were introduced to the purposes of process modeling and the Architecture of Integrated Information Systems (ARIS) framework was explained in detail. In one comprehensive assignment, the students had to design "as-is" and "to-be" process models for selected case studies. Thus, they developed the theoretical knowledge and had hands-on experiences with designing process models using ARIS.

In the subject "Projects in Process Engineering", students had the opportunity to apply this knowledge in a real world context (Rosemann, Sedera \& Sedera 2000). Organized in four teams of four students each, over a period of 12 weeks they analyzed the following processes at a Queensland Government department: Procurement, Corporate Card, Leave Request, and Recruitment. The students used the ARIS-Toolset 4.1 for the design of the "as-is" and "to-be" models. Some of the students also performed an ARIS-based process simulation. All process models were presented to the contact people from the collaborating department.

Students (or "novices") were considered to be appropriate subjects for this pilot test. In the words of Vessey and Conger (1994), students might actually be more appropriate subjects when comparing/evaluating analysis techniques for two reasons:

2 A copy of the complete instrument can be obtained from the authors on request. 
"First,...it is easier to teach them (novices) to apply a specific methodology than it is to teach new methods to people who may already be experts in developing systems...Second, examining expert problem solving can be quite difficult, since experts automate their processes to the point at which they are no longer able to articulate what they are doing."

Furthermore, we followed the main guidelines of Rein (1994) regarding the use of students as substitutes for business teams. The selected task was a real project for the student and it accounted for a significant portion of each student's grade.

\section{RESULTS}

The questionnaire was distributed in the last seminar of the semester (semester 1, 2000) and the students were asked to either complete it there and then, or return it within seven days. Seven of the 13 students present at the seminar finally returned the questionnaire, giving a response rate of 54 percent. Table 2 profiles the seven respondents.

\begin{tabular}{|l|l|}
\hline Item & \\
\hline Working in business: & 85 \\
\hline$<2$ years & 15 \\
\hline $2-5$ years & 0 \\
\hline $5-15$ years & 0 \\
\hline$>15$ years & \\
\hline Involved in process modeling: & 57 \\
\hline$<1$ year & 43 \\
\hline $1-2$ years & 0 \\
\hline $2-5$ years & 0 \\
\hline$>5$ years & \\
\hline Used ARIS-Toolset: & 100 \\
\hline < year & 0 \\
\hline $1-3$ years & 0 \\
\hline$>3$ years & \\
\hline Most recent version of ARIS-Toolset used: & 100 \\
\hline ARIS-Toolset 4.1 & \\
\hline Primary purpose of process modeling: & 57 \\
\hline Organizational processes & 43 \\
\hline IT processes & \\
\hline My organization: & 100 \\
\hline Public sector & 0 \\
\hline Private sector & \\
\hline
\end{tabular}

Table 2. Profile of Respondents.

All participating students were post-graduate students with a maximum of two years working experience; one student had between 2 and 5 years working experience. They were involved in process modeling for a maximum of two years. All students had less than one year's experience with the conceptual ARIS framework as well as with the corresponding ARIS-Toolset. Four students identified the redesign of organisational processes as their main modeling purpose. Three students saw their objectives rather in the redesign of IT processes.

Fifty-seven percent (four of the seven) of the participants answered that they only used one view - the process view - to design business processes with the ARIS-Toolset. These respondents indicated that the process view included a sufficient set of symbols to represent all the concepts they needed. However, three of the four ( 75 percent) also indicated that they used one view only because that was the way they were trained originally to do process modeling. Most interestingly also, three of the four ( 75 percent) indicated that they created new symbols within the one view to enhance their modeling capabilities. So, while all four respondents felt that there were sufficient symbols in the one view for their modeling activities, three of the four found a need to enhance the single view with new symbols to handle all their modeling requirements. Those who used more than one view (43 percent) always started with the process view. The models were usually completed with models derived from the organizational and the function views. Asked which models they are likely to use for their future modeling, respondents selected all four views besides the process view with the data and the function views being the most popular.

Of the three respondents who used more than one view for their modeling, only one student saw a need to model real-world objects ("things"). In the context of the process view only, using an existing symbol in the process 
view and changing its meaning did this modeling of things. The data and the output view were regarded as relevant views for modeling real-world objects if there was such a need.

Sixty-six percent (two of the three) of the respondents saw limitations in incorporating all the different business rules of the situation being modeled. Similar to the limitations involving the modeling of real-world objects, the respondents saw the solution in changing the meaning of existing symbols provided in the process view. The other views were regarded as not useful to depict business rules.

One hundred percent of respondents who modeled using more than one view (three out of three) wanted to describe the scope and boundary of the overall system. However, the answers regarding how to model the system's scope and boundary varied significantly. Their responses included that it is not possible to describe the scope and boundary in ARIS, that existing symbols in the process view can be used, and that a redefinition of existing symbols in the process view is sufficient. Asked whether symbols from other views might be helpful to defining the scope and boundary of a system, only one response suggested the use of symbols from the data and output views.

Again, one hundred percent of respondents who modeled using more than one view (three out of three) agreed that a decomposition of models into more detailed models is required. While 66 percent of all answers indicated that existing symbols provided in the process view could be used for this purpose, 33 percent answered that a decomposition is not possible. Approaches to decompose models using symbols from other views included symbols from the function, the organisational, the data, and the output views.

All three multi-view respondents perceived the function view as useful. Furthermore, leaving the companymandated standard set of process modeling views to one side, the preferred combination of grammars (two from three respondents) was the process, function and organisational views.

All but one student (six out of seven) responded that they were working in a project team while doing process modeling. Seventy-one percent of all respondents used only the process view. The organizational view was used in all cases that included more than one view (two out of seven). In one case also function and data models were designed.

\section{DISCUSSION OF RESULTS}

In the light of the derived propositions, this study gives some initial valuable feedback.

Green and Rosemann (2000) proposed that the ontological weakness of a missing symbol for things, class or kind leads to a lack of clarity, if real-world objects are supposed to be modeled. However, only one of three multi-view respondents saw a need at all to model real-world objects. Thus, this situation could be a case in which a theoretically derived ontological weakness is of only minor consequence for practical use.

It was predicted that, because of the fact that the process view does not have representations for conceivable state space, lawful state space, conceivable event space, and lawful event space, a sufficient capability to identify and model all relevant business rules might not be given in ARIS. This proposition was supported by 66 $\%$ of the multi-view respondents. More importantly, even when all five views of ARIS were taken into account, respondents still maintained they could not model all necessary business rules. Hence, this situation could possibly be a weakness of ARIS.

Moreover, it was proposed that, because of the missing representations for system, system composition, system environment, system structure, system decomposition, and coupling, the process view's usefulness for defining the scope and boundaries of a system is undermined. Moreover, the usefulness of the process view for undertaking "good decompositions" during analysis is degraded. The fact that all multi-view respondents stressed the importance of defining precisely the scope and boundaries of a system and the opportunity to further decompose a model indicates that ARIS does not support this capability sufficiently. The strategies suggested by the respondents to overcome this problem vary significantly and further investigations are necessary.

Finally, Green and Rosemann (2000) proposed that the function view is completely ontologically redundant when compared to the combination of process view, data view, and either organizational view or output view. Surprisingly, all three multi-view respondents saw the function view as far from useless. As the functions of the function view are also described in the context of the business processes in the process view, the function view does not seem to add value. One possible explanation for the contrary response received here could be that the user of ARIS appreciates redundancy as a mechanism to handle complexity in modeling. Table 3 summarizes the initial insights gained on the Green and Rosemann (2000) propositions. 


\begin{tabular}{|c|c|}
\hline 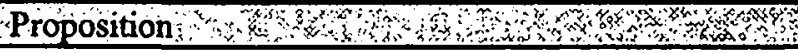 & 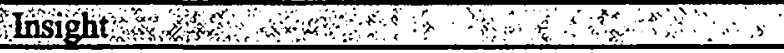 \\
\hline \multicolumn{2}{|l|}{ Process view only: } \\
\hline P1 - another symbol/view for thing, class/kind & Little support \\
\hline P2 - another symbol/view for business rules & Supported \\
\hline $\begin{array}{l}\text { P3 - another symbol/view for scope and boundary of } \\
\text { system, and to assist in decompositions }\end{array}$ & Supported \\
\hline \multicolumn{2}{|l|}{ More than one view in combination: } \\
\hline P4 - another symbol/view for business rules & Supported \\
\hline $\begin{array}{l}\text { P5 - another symbol/view for scope and boundary of } \\
\text { system, and to assist in decompositions }\end{array}$ & Supported \\
\hline P6 - function view is of limited use & $\begin{array}{l}\text { Unsupported - perhaps ontological redundancy helps } \\
\text { manage complexity }\end{array}$ \\
\hline
\end{tabular}

Table 3. Summary of Insights gained on Propositions.

\section{LIMITATIONS, SUMMARY, AND FUTURE WORK}

This is a preliminary study. It gives some initial feedback regarding the Green and Rosemann (2000) propositions. Furthermore, this work has assisted the development of a data-gathering instrument. From the responses received to this initial version of the instrument, it is clear, inter alia, that the order of questions in section B needs to be adjusted and that further explanatory opportunities need to be provided particularly for responses regarding the use of the function view. Nevertheless, the number of the respondents (7) and their modest experience in ARIS (less than one year) make it obvious that any inferences from this initial study are necessarily limited and generalizations of the results are not possible. Accordingly, further investigations with professional (practitioner and academic) ARIS users are indispensable.

This work has developed and pilot tested a survey instrument for gathering data to test propositions derived by Green and Rosemann (2000) from the ontological evaluation of a popular instance of an integrated process modeling framework - ARIS. The work has provided valuable feedback on the instrument and it has suggested a number of improvements to the instrument for future empirical data gathering. Furthermore, the feedback from the limited responses indicates that,

the need to model real-world objects - things, classes/kinds - was not generally perceived. Where the need was perceived, it was accomplished by using an existing symbol and changing its meaning.

It was generally perceived that within the process view, and even when other views were added to the process view, severe limitations existed in the modeling of all necessary business rules.

There is a strong perceived need to represent the scope and boundary of a system, and to be able to decompose the system when using integrated process modeling. Within the process view, and even across the five views in combination, the respondents generally either could not model and decompose the scope and boundary of a system, or they used existing symbols and changed their meaning to meet their purposes.

The proposition that, because the function view is completely ontologically redundant when compared to the combination of process, data, and either organizational or output views, the function is of limited use is generally unsupported.

In further work, we intend to refine the data-gathering instrument according to the feedback we have received in this limited study. Then, we will administer the refined instrument to a sample of academic and practitioner ARIS process modelers located both in Australia and overseas. This expanded, more experienced sample will provide sufficient data to dramatically improve the inferences that may be made about the propositions and the generalization of the results.

\section{REFERENCES}

Bansler, J. P. \& Bodker, K. (1993) "A reappraisal of structured analysis: Design in an organizational context", ACM Transactions on Information Systems, 11(2), pp. 165-193.

Batra, D., Hoffer, J. A. and Bostrom, R. P. (1990) "Comparing representations with relational and EER models", Communications of the ACM, 33(2), pp. 126-139.

Bunge, M. (1977) Treatise on Basic Philosophy: Volume 3: Ontology I: The Furniture of the World, Reidel, Boston.

Davenport, T. H. (1993) Process Innovation. Reengineering Work through Information Technology, Boston.

Floyd, C. (1986) "A comparative evaluation of system development methods", In Information Systems Design Methodologies: Improving the Practice, North-Holland, Amsterdam, pp. 19-37.

Green, P. (1996) An Ontological Analysis of ISAD Grammars in Upper CASE Tools, Unpublished PhD 
Thesis, University of Queensland, Brisbane, Australia.

Green, P. (1997) "Use of Information Systems Analysis and Design (ISAD) Grammars in Combination in Upper CASE Tools - An Ontological Evaluation", In Proceedings of the $2^{\text {nd }}$ CAiSE/IFIP8.1 International Workshop on the Evaluation of Modeling Methods in Systems Analysis and Design (EMMSAD'97). Barcelona, Spain, pp. 1-12.

Green P. and Rosemann M. (2000) "Integrated Process Modeling: An Ontological Evaluation", Information Systems, 25(2), pp. 73-87.

Hammer, M. (1990) "Reengineering Work: Don't Automate, Obliterate", Harvard Business Review, 68(7-8), pp. 104-112.

Karam, G. M. and Casselman, R. S. (1993) "A cataloging framework for software development methods", IEEE Computer, Feb., pp. 34-46.

Rein, G. L. (1994) A Prolegomena on the Use of Student Subjects in Group Work Research, Working Paper 775, State University of New York.

Rosemann, M., and Green, P. (2000) "Integrating Multi-Perspectives into Ontologies", Proceedings of the International Conference on Information Systems - ICIS 2000, Eds.: W. J. Orlikowski et al., Brisbane, 10-13 December 2000.

Rosemann, M., Sedera, W. and Sedera, D. (2000) "Industry-oriented Education in Enterprise Systems", in Proceedings of the $11^{\text {th }}$ Australasian Conference on Information Systems (ACIS 2000), eds. G G Gable and $M$. Vitale. Brisbane, 6-8 December.

Scheer, A.-W. (1999) ARIS - Business Process Frameworks, $2^{\text {nd }}$ ed., Springer, Berlin.

Vessey, I. and Conger, S. (1994) "Requirements Specification: Learning Object, Process, and Data Methodologies", Communications of the ACM, 37(5), pp. 102-113.

Wand, Y. and Weber, R. (1989a) "A model of control and audit procedure change in evolving data processing systems", The Accounting Review, LXIV(1), pp. 87-107.

Wand, Y. and Weber, R. (1989b) "An ontological evaluation of systems analysis and design methods", in Information System Concepts: An In-depth Analysis, eds. E. D. Falkenberg, P. Lindgreen, North-Holland, pp. 79-107.

Wand, Y. and Weber, R. (1990a) "An ontological model of an information system", IEEE Transactions on Software Engineering, 16(11), pp. 1281-1291.

Wand, Y. and Weber, R. (1990b) "Mario Bunge's Ontology as a formal foundation for information systems concepts", in Studies on Mario Bunge's Treatise, eds. P. Weingartner, G. J. W. Dorn, Rodopi. Atlanta, 123149.

Wand, Y. and Weber, R. (1991) "A unified model of software and data decomposition", in Proceedings of the $12^{\text {th }}$ International Conference on Information Systems (ICIS 91), eds. J. DeGross, I. Benbasat, G. DeSanctis, C.M. Beath, New York, pp. 101-110.

Wand, Y. and Weber, R. (1993) "On the ontological expressiveness of information systems analysis and design grammars", Journal of Information Systems, 3(4), pp. 217-237.

Wand, Y. and Weber, R. (1995) "On the deep structure of information systems", Information Systems Journal, 5, pp. 203-223.

Weber, R. (1997) Ontological Foundations of Information Systems, Coopers \& Lybrand Accounting Research Methodology. Monograph No. 4. Melbourne.

Weber, R. and Zhang, Y. (1996) "An analytical evaluation of NIAM's grammar for conceptual schema diagrams", Information Systems Journal, 6(2), pp. 147-170.

\section{ACKNOWLEDGEMENTS}

We would like to thank the students of the subject ITN246/291 Project in Process Engineering at Queensland University of Technology, Brisbane, for their participation in this study. 